\title{
SARS-CoV-2 Infection and Placental Pathology
}

\section{Infecção por SARS-CoV-2 e patologia placentária}

\author{
Caio Ribeiro Vieira Leal ${ }^{1}$ Rayra Amana Macêdo Maciel ${ }^{1}$ Mário Dias Corrêa Júnior $^{1}$ Me $^{\circledR}$
}

${ }^{1}$ Department of Gynecology and Obstetrics, Hospital das Clínicas, Faculdade de Medicina, Universidade Federal de Minas Gerais, Belo Horizonte, Minas Gerais, MG, Brazil

Address for correspondence Caio Ribeiro Vieira Leal, Avenida Professor Alfredo Balena 110, $4^{\circ}$ andar, Santa Efigênia, Belo Horizonte, Minas Gerais, MG, 31100-000, Brazil (e-mail: lealcaiorv@gmail.com).

Rev Bras Ginecol Obstet 2021;43(6):474-479.

\begin{abstract}
Keywords

- SARS-CoV-2

- Covid-19

- pregnancy

- placenta

- pathology

\section{Resumo}
Palavras-chave
- SARS-CoV-2
- Covid-19
- gravidez
- placenta
- patologia

Placental pathophysiology in SARS-CoV-2 infection can help researchers understand more about the infection and its impact on the maternal/neonatal outcomes. This brief review provides an overview about some aspects of the placental pathology in SARSCoV-2 infection. In total, 11 papers were included. The current literature suggests that there are no specific histopathological characteristics in the placenta related to SARSCoV-2 infection, but placentas from infected women are more likely to show findings of maternal and/or fetal malperfusion. The most common findings in placentas from infected women were fibrin deposition and intense recruitment of inflammatory infiltrates. The transplacental transmission of this virus is unlikely to occur, probably due to low expression of the receptor for SARS-CoV-2 in placental cell types. Further studies are needed to improve our knowledge about the interaction between the virus and the mother-fetus dyad and the impact on maternal and neonatal/fetal outcomes.

A fisiopatologia da placenta na infecção por SARS-CoV-2 pode ajudar os pesquisadores a entender mais sobre a infecção e seu impacto nos resultados maternos/neonatais. Esta revisão breve fornece uma visão geral sobre alguns aspectos da patologia placentária na infecção por SARS-CoV-2. Ao todo, 11 artigos foram incluídos. A literatura atual sugere que não há características histopatológicas específicas nas placentas relacionadas à infecção por SARS-CoV-2, mas as placentas de mulheres infectadas têm maior probabilidade de apresentar achados de má perfusão materna e/ou fetal. Os achados mais comuns em placentas de mulheres infectadas foram deposição de fibrina e intenso recrutamento de infiltrado inflamatório. A transmissão transplacentária deste vírus é improvável, devido à baixa expressão do receptor para SARS-CoV-2 em tipos de células da placenta. Mais estudos são necessários para melhorar nosso conhecimento sobre a interação entre o vírus e a díade mãe-feto e o impacto nos resultados maternos e neonatais/fetais.
\end{abstract}

received

September 29, 2020

accepted

February 18, 2021

published online

June 2, 2021
DOI https://doi.org/

10.1055/s-0041-1730291. ISSN $0100-7203$.
(C) 2021. Federação Brasileira de Ginecologia e Obstetrícia. All rights reserved.

This is an open access article published by Thieme under the terms of the Creative Commons Attribution License, permitting unrestricted use, distribution, and reproduction so long as the original work is properly cited. (https://creativecommons.org/licenses/by/4.0/)

Thieme Revinter Publicações Ltda., Rua do Matoso 170, Rio de Janeiro, RJ, CEP 20270-135, Brazil 


\section{Introduction}

The most significant public health problem of the last decades is the coronavirus disease 2019 (Covid-19) pandemic, caused by the novel severe acute respiratory syndrome coronavirus 2 (SARS-CoV-2), responsible for more than 1 million deaths worldwide. ${ }^{1}$ Some conditions have been associated with a higher risk of developing a severe illness, like advanced age, cardiovascular disease, diabetes mellitus, and hypertension. ${ }^{2}$ However, data on the impact of the SARS$\mathrm{CoV}-2$ infection in pregnant women and in their fetuses or newborns are controversial. The available literature suggests that pregnant women have outcomes and clinical courses comparable to those of non-pregnant women of reproductive age, ${ }^{3,4}$ and the newborns of infected mothers do not often show adverse clinical outcomes, ${ }^{5}$ but there is few goodquality evidence to draw unbiased conclusions. ${ }^{6}$ In any pregnancy infection, the placental pathophysiology can help researchers understand more about the disease and its impact on the maternal and neonatal outcomes. ${ }^{7}$ The placenta is a transient pregnancy-related organ whose main function is to enable the maternal-fetal exchange of certain substances. ${ }^{8}$ Some viruses can cross the placental barrier and infect the fetus, like the Zika virus, the cytomegalovirus, the rubella virus, and the herpesvirus. ${ }^{9}$ So far, there is only one case report that showed unequivocal transplacental transmission of SARS-CoV-2. ${ }^{10}$ There are many other papers about the vertical transmission of COVID-19, but no other convincing evidence has been found for the vertical transmission of this virus. ${ }^{11}$ Besides being the possible key point for a fetal infection in pregnancy, the placenta itself can also be affected, morphologically and functionally, by the infection. ${ }^{12}$ The aim of this brief review is to provide an overview about the data available in the literature about placental pathology in SARS-CoV-2 infection.

\section{Methods}

This brief and non-systematic review was based on a search carried out independently by two authors (CRVL and RAMM) on the PubMed, Scopus, SciELO and Cochrane databases. The following search terms were used: placenta; placental pathology; SARS-CoV-2; and coronavirus. Papers were selected after screening titles and articles. After data extraction and critical analysis, 11 case reports or series about placental alterations and pathophysiology in SARS-CoV-2 infection were included. ${ }^{10,13-22}$

\section{Results}

There are limited studies on SARS-CoV-2 infection and placental pathology. The most important aspects of each article found are shown in table $\mathbf{1}$.

So far, there is no evidence that SARS-CoV-2 can induce specific histopathological changes in placentas. ${ }^{15,16,21,22}$ Some studies identified SARS-CoV-2 proteins in placental tissues or cells. Facchetti et al. ${ }^{17}$ identified the virus in the villous syncytiotrophoblast, endothelial cells, fibroblasts, in maternal macrophages, in Hofbauer cells, and in fetal intravascular mononuclear cells. Hosier et al. ${ }^{13}$ and Patanè et al. ${ }^{20}$ found the virus in the syncytiotrophoblast, and Hsu et al. ${ }^{14}$ identified virus proteins in chorionic villi endothelial cells and in trophoblasts.

Vivanti et al. ${ }^{10}$ presented the first proven case of transplacental transmission of SARS-CoV-2. A 23-year-old pregnant woman infected by SARS-CoV-2 was submitted to a cesarean-section in full isolation. Amniotic fluid was collected before membrane rupture and tested positive for SARS$\mathrm{CoV}-2$ genes, as well as the placenta and other maternal and fetal tissues.

The most common findings in the placenta of pregnant women infected with SARS-CoV-2 are fibrin deposition and intense recruitment of inflammatory infiltrates. Fibrin depositions have been observed in three different patterns: subchorionic deposition, ${ }^{18,22}$ deposition inside the villi, ${ }^{21}$ and perivillous deposition, ${ }^{10,13,17,21}$ and the last pattern was the most observed. The intense inflammatory infiltrates were composed mainly of macrophages, ${ }^{17,20}$ neutrophils, ${ }^{17} \mathrm{~T}$ lymphocytes $^{13,14}$ and histiocytes. ${ }^{14}$

In the study conducted by Smithgall et al., ${ }^{16} 51$ thirdtrimester placentas from SARS-CoV-2-positive pregnant women (study group) and 25 third-trimester placentas from SARS-CoV-2-negative pregnant women (control group) were examined, and data were compared. As described before, no specific viral cytopathic modifications or evidence of vertical transmission were observed, but the study group showed evidence of maternal-fetal vascular malperfusion, with more villous agglutination $(p=0.003)$ and subchorionic thrombi $(p=0.026)$ than the control group. Ferraiolo et al. ${ }^{18}$ also presented a case report of a third trimester SARS-CoV-2positive placenta with villous agglutination.

Data also suggests that there is maternal and/or fetal malperfusion. Although the case reported by Hosier et al. ${ }^{13}$ showed no decidual vasculopathy, the case report by Hsu et al. ${ }^{14}$ demonstrated maternal vascular malperfusion (decidual hypertrophic arteriolopathy), with no fetal vascular malperfusion and, as aforementioned, Smithgall et al. ${ }^{16}$ showed both maternal vascular malperfusion (decidual vasculopathy, intervillous thrombus, villus agglutination, and subchorionic thrombus) and fetal vascular malperfusion (avascular villi, fetal thrombotic vasculopathy, and chorangiosis). The study by Shanes et al. ${ }^{19}$ indicated that placentas of SARS-CoV-2-positive pregnant women, compared to the control group (women with other medical conditions), were significantly more likely to exhibit intervillous thrombi $(p=0.0002)$ and at least one feature of maternal vascular malperfusion $(p=0,046)$, such as unusual or damaged maternal vessels.

The case series studied by Patanè et al. ${ }^{20}$ presented 22 SARS-CoV-2-infected pregnant women. There were only two women whose newborns had SARS-CoV-2-positive nasopharyngeal swabs, and their placentas showed chronic intervillositis, accompanied by the existence of macrophages both in the intervillous and the villous spaces. Curiously, there were no significant alterations on the placenta of infected mothers whose newborns tested were negative. 
Table 1 Summary of papers about placental pathology in SARS-CoV-2 infection

\begin{tabular}{ll}
\hline Authors & Study characteristics \\
\hline Vivanti et al. $^{10}$ & $\begin{array}{l}\text { Case report of transplacental } \\
\text { transmission of SARS-CoV-2 in a } \\
\text { pregnant woman in the third } \\
\text { trimester }\end{array}$ \\
Hosier et al. $^{13}$ & $\begin{array}{l}\text { Case report of second trimester } \\
\text { SARS-CoV-2-infected pregnancy } \\
\text { complicated by severe } \\
\text { preeclampsia and placental } \\
\text { abruption }\end{array}$
\end{tabular}

Hsu et al. ${ }^{14}$

Case report of third trimester SARS-CoV-2-infected pregnant woman

Hecht et al. ${ }^{15}$ Case series and comparative study between 19 SARS-CoV-2 infected pregnant women and 3 sets of controls

Smithgall et al. ${ }^{16}$ Case series and comparative study between 51 SARS-CoV-2-infected pregnant women and 25 SARS-CoV-2-negative pregnant women

Facchetti et al. ${ }^{17}$ Case series of 15 SARS-CoV-2infected pregnant women

Ferraiolo et al. ${ }^{18}$ Case report of positive placental swabs for SARS-CoV-2 in an asymptomatic pregnant woman

Shanes et al. ${ }^{19}$ Case series and comparative study between 16 SARS-CoV-2 infected pregnant women and 2 populations of controls

Patanè et al. ${ }^{20}$ Case series of 22 SARS-CoV-2infected pregnant women in the third trimester

Chen et al. ${ }^{21}$

Case series of three SARS-CoV-2infected pregnant women in the third trimester

Taglauer et al. ${ }^{22}$ Case series and comparative study between 15 SARS-CoV-2-infected pregnant women and 10 SARSCoV-2-negative pregnant women

\section{Main findings}

The first case of proven transplacental transmission of SARS-CoV-2. The RTPCR was positive for SARS-CoV-2 genes on the placenta, amniotic fluid and maternal, and fetal blood. Placental histological examination revealed diffuse perivillous fibrin deposition with infarction and acute and chronic intervillositis.

Placental histological examination showed diffuse perivillous fibrin deposition and an inflammatory infiltrate consistent with histiocytic intervillositis. There were no features of decidual vasculopathy. Placenta and umbilical cord tested positive for SARS-COV-2 RNA. Virus proteins were localized predominantly in the syncytiotrophoblast cells.

Placental histological examination showed signs of maternal vascular malperfusion with hypertrophic arteriolopathy, but no fetal vascular malperfusion. There were signs of acute uterine hypoxia (subchorionic laminar necrosis) superimposed on chronic uterine hypoxia (extravillous trophoblasts and focal chronic villitis). Virus proteins were identified in chorionic villi endothelial cells and in trophoblasts.

There was no specific gross or characteristic histopathology present in the placentas, including the only two infected placentas.

There were no specific histopathological characteristics in the placentas related to SARS-CoV-2 infection. None of the placentas tested positive for SARS-CoV-2. Maternal/fetal vascular malperfusion was identified in infected women, and their placentas showed more villous agglutination and subchorionic thrombi compared with non-infected women.

Only 1 of the 15 placentas tested positive for SARS-CoV-2 genes. The comparison between this placenta and the other 14 showed no significant morphological differences, except for the prominent intervillous inflammation (showing variable changes compatible with fetal vascular malperfusion).

Placental histological examination did not show substantial macroscopic alterations, except for mild to moderate subchorionic deposition of fibrin, for the presence of a single ischemic area in the thickness of the chorionic disc, for the appearance of villous agglutination, and for multiple organizing intervillous hemorrhages.

Third-trimester placentas were significantly more likely to show decidual arteriopathy or at least one characteristic of maternal vascular malperfusion (MVM), such as abnormal or injured maternal vessels and intervillous thrombi, when compared to controls. Placentas were not tested for SARS-CoV-2.

Only two newborns had SARS-CoV-2-positive nasopharyngeal swabs, whose placentas showed chronic intervillositis. On placental histological examination, no significant changes were observed in the other infected pregnant women.

Placental histological examination showed various degrees of fibrin deposition inside and around the villi, but no pathological change of villitis or chorioamnionitis. There were no specific placental morphologic changes related to SARS-CoV-2 infection.

There were no specific histopathological characteristics in the placentas related to SARS-CoV-2 infection. Placentas from infected women were notable for the presence of signs of inflammation and fibrin deposition, mostly intervillous and subchorionic deposition.

Abbreviations: RT-PCR, real-time polymerase chain reaction; SARS-CoV-2, severe acute respiratory syndrome coronavirus 2. 


\section{Discussion}

To date, little is known about placental pathology in SARSCoV-2 infection, but the current literature suggests that there are no specific changes in the placenta of infected pregnant women. As aforementioned, the most common findings in the placenta of SARS-CoV-2-infected pregnant women are fibrin deposition and intense recruitment of inflammatory infiltrates. Compared to controls, the placentas of infected women showed a higher probability of exhibiting intervillous thrombi and at least one feature of maternal vascular malperfusion, ${ }^{19}$ more villous agglutination, and subchorionic thrombi. ${ }^{16}$

Intervillous thrombi is the presence of a localized area of thrombosis in the chorionic villous stroma, while perivillous fibrinoid deposition is defined by the presence of fibrinoid material deposition in the intervillous space, and villous agglutination occurs when the distal villi are agglutinated by fibrin and bridging syncytial knots. ${ }^{23}$ These patterns can be associated with processes of maternal malperfusion, such as placental insufficiency, fetal growth restriction, preeclampsia, thrombophilia, cardiovascular disease, renal abnormalities, or glucose intolerance. ${ }^{23-26}$ Acute inflammatory lesions of the placenta are defined by diffuse infiltration of neutrophils and can involve every compartment of the placenta. ${ }^{23,25}$ Chronic inflammatory lesions of the placenta are characterized by the infiltration of lymphocytes, plasma cells and macrophages, which may be a result of infections or may have an immune origin. ${ }^{27}$ The main chronic inflammatory lesions of the placenta are villitis, chronic chorioamnionitis, and chronic deciduitis, ${ }^{27}$ but chronic inflammation can also involve every compartment in the placenta, such as the intervillous space (intervillositis) or the umbilical cord (funisitis). ${ }^{28}$ In our research, four articles showed two chronic inflammatory lesions in placentas from SARS-CoV-2infected pregnant women: chronic intervillositis $10,13,20$ and chronic villitis. ${ }^{14}$ Both entities are usually reactions to infection, especially within the toxoplasmosis, other (syphilis, varicella-zoster, parvovirus B19), cytomegalovirus, and herpes simplex virus (TORCH) group, but when infectious causes are ruled out, they are called chronic intervillositis of unknown etiology (CIUE) and villitis of unknown etiology, both related to adverse obstetric outcomes, such as intrauterine growth restriction, preterm birth, and pregnancy loss. ${ }^{28-30}$

Specifically when talking about viral infections, some patterns are well studied, such as the correlation between maternal cytomegalovirus infection to the presence of chronic lymphoplasmacytic villitis and hemosiderin deposition, ${ }^{23,26}$ as well as some reports of nonspecific intervillositis in the setting of the Zika and Dengue virus. ${ }^{19}$ It seems that there is no association between the presence of chronic or even acute specific inflammatory patterns and placental findings of SARS-CoV-2-infected women, ${ }^{19}$ only nonspecific inflammatory infiltrates composed of macrophages, neutrophils, T lymphocytes and histiocytes, as aforementioned.

Data on placental pathology in diseases caused by other coronaviruses, the severe acute respiratory syndrome coro- navirus (SARS-CoV) and the Middle East respiratory syndrome coronavirus (MERS-CoV), are scarce. $\mathrm{Ng}$ et $\mathrm{al}^{31}$ reported a case series of 7 placentas from pregnant women infected with SARS-CoV during the pandemic that occurred in Asia in 2003. Similar to SARS-CoV-2, there were no specific changes in those placentas. Two placentas of convalescent women who had the disease in the first trimester were normal, three placentas delivered in the acute stage of the disease showed increased subchorionic and intervillous fibrin deposition, and two placentas of convalescent women who had the disease in the third trimester showed extensive fetal thrombotic vasculopathy with sharply demarcated zones of avascular fibrotic villi (both had intrauterine growth restriction, oligohydramnios, and newborns small for gestational age). Data on MERS-CoV and placental pathology are even scarcer, but it seems that there is no relationship between this virus and specific placental disorders. ${ }^{32}$

In regard to the vertical transmission of SARS-CoV-2, most studies ${ }^{11,33}$ show that this mode of transmission is unlikely to occur. Only Vivanti et al. ${ }^{10}$ could prove the transplacental transmission of this virus; therefore, if vertical transmission exists, it happens at low rates and possibly in selected cases. One of the cornerstones in this issue is how the virus infects the cells: through the angiotensin-converting enzyme 2 (ACE-2) receptor and the transmembrane serine protease 2 (TMPRSS-2), widely expressed in many tissues. ${ }^{34,35}$ It is well established that the more the cell expresses ACE-2, the greater the chances it will be infected by coronaviruses. ${ }^{36}$ There is no consensus about how much placental tissue express ACE-2 and TMPRSS-2. Taglauer et al. ${ }^{22}$ showed a predominance of ACE-2 expression in comparison with TMPRSS- 2 in placenta from infected women, but there was a significant decrease in ACE-2 expression in those placentas compared to those of non-infected pregnant women. PiqueRegi et al. ${ }^{37}$ reported that placental tissues poorly express ACE-2 and TMPRSS-2, but receptors for other viruses that cause congenital infections (such as cytomegalovirus and the Zika virus) are highly expressed by placental cell types, and that is why vertical transmission for SARS-CoV-2 is unlikely to occur. The expression of ACE-2 in the placenta can be increased in some diseases, such as preeclampsia, ${ }^{38}$ so there would be a theoretical increased risk of vertical transmission in this setting, for example. Additional studies are needed to evaluate the expression of ACE- 2 and TMPRSS- 2 in placental cells in physiological and pathological conditions to investigate the infection and transmission of SARS-CoV-2.

\section{Conclusion}

In conclusion, in the present review, specific changes in the placentas of SARS-CoV-2-infected pregnant women were not found, but findings of maternal and/or fetal malperfusion were more likely to occur in infected than in non-infected women. The most common findings in the placentas from infected women were fibrin deposition and intense recruitment of inflammatory infiltrates. Little is known about placental pathology in SARS-CoV-2 infection, and further good evidence-based studies are needed in order to improve 
our knowledge about the interaction between the virus and the mother-fetus dyad and the impact on maternal and neonatal/fetal outcomes.

\section{Conflict of Interests}

The authors have no conflict of interests to declare.

\section{References}

1 World Health Organization. WHO Coronavirus Disease (COVID19) Dashboard [Internet]. 2020. [cited 2020 Oct 12]. Available from: https://covid19.who.int/

2 Petrilli CM, Jones SA, Yang J, Rajagopalan H, O'Donnell L, Chernyak Y, et al. Factors associated with hospital admission and critical illness among 5279 people with coronavirus disease 2019 in New York City: prospective cohort study. BMJ. 2020;369:m1966. Doi: 10.1136/bmj.m1966

3 Qiancheng X, Jian S, Lingling P, Lei H, Xiaogan J, Weihua, L, et al. sixth batch of Anhui medical team aiding Wuhan for COVID-19. Coronavirus disease 2019 in pregnancy. Int J Infect Dis. 2020; 95:376-383. Doi: 10.1016/j.ijid.2020.04.065

4 Della Gatta AN, Rizzo R, Pilu G, Simonazzi G. Coronavirus disease 2019 during pregnancy: a systematic review of reported cases. Am J Obstet Gynecol. 2020;223(01):36-41. Doi: 10.1016/j. ajog.2020.04.013

5 Kyle MH, Glassman ME, Khan A, Fernández CR, Hanft E, Emeruwa UN, et al. A review of newborn outcomes during the COVID-19 pandemic. Semin Perinatol. 2020;44(07):151286. Doi: 10.1016/j. semperi.2020.151286

6 Juan J, Gil MM, Rong Z, Zhang Y, Yang H, Poon LC. Effect of coronavirus disease 2019 (COVID-19) on maternal, perinatal and neonatal outcome: systematic review. Ultrasound Obstet Gynecol. 2020;56(01):15-27. Doi: 10.1002/uog.22088

7 Koi H, Zhang J, Parry S. The mechanisms of placental viral infection. Ann N Y Acad Sci. 2001;943:148-156. Doi: 10.1111/ j.1749-6632.2001.tb03798.x

8 Burton GJ, Fowden AL. The placenta: a multifaceted, transient organ. Philos Trans R Soc Lond B Biol Sci. 2015;370 (1663):20140066. Doi: 10.1098/rstb.2014.0066

9 Arora N, Sadovsky Y, Dermody TS, Coyne CB. Microbial vertical transmission during human pregnancy. Cell Host Microbe. 2017; 21(05):561-567. Doi: 10.1016/j.chom.2017.04.007

10 Vivanti AJ, Vauloup-Fellous C, Prevot S, Zupan V, Suffee C, Cao JD, et al. Transplacental transmission of SARS-CoV-2 infection. Nat Commun. 2020;11(01):3572. Doi: 10.1038/s41467-020-17436-6

11 Simões E Silva AC, Leal CRV. Leal CRV. Is SARS-CoV-2 vertically transmitted? Front Pediatr. 2020;8:276. Doi: 10.3389/ fped.2020.00276

12 Rosenberg AZ, Yu W, Hill DA, Reyes CA, Schwartz DA. Placental pathology of Zika virus: viral infection of the placenta induces villous stromal macrophage (Hofbauer cell) proliferation and hyperplasia. Arch Pathol Lab Med. 2017;141(01):43-48. Doi: 10.5858/arpa.2016-0401-OA

13 Hosier H, Farhadian SF, Morotti RA, Deshmukh U, Lu-Culligan A, Campbell KH, et al. SARS-CoV-2 infection of the placenta. J Clin Invest. 2020;130(09):4947-4953. Doi: 10.1172/JCI139569

14 Hsu AL, Guan M, Johannesen E, Stephens AJ, Khaleel N, Kagan N, et al. Placental SARS-CoV-2 in a pregnant woman with mild COVID-19 disease. J Med Virol. 2021;93(02):1038-1044. Doi: 10.1002/jmv.26386

15 Hecht JL, Quade B, Deshpande V, Mino-Kenudson M, Ting DT, Desai $\mathrm{N}$, et al. SARS-CoV-2 can infect the placenta and is not associated with specific placental histopathology: a series of 19 placentas from COVID-19-positive mothers. Mod Pathol. 2020;33 (11):2092-2103. Doi: 10.1038/s41379-020-0639-4

16 Smithgall MC, Liu-Jarin X, Hamele-Bena D, Cimic A, Mourad M, Debelenko L, Chen X. Third-trimester placentas of severe acute respiratory syndrome coronavirus 2 (SARS-CoV-2)-positive women: histomorphology, including viral immunohistochemistry and in-situ hybridization. Histopathology. 2020;77(06): 994-999. Doi: 10.1111/his.14215

17 Facchetti F, Bugatti M, Drera E, Tripodo C, Sartori E, Cancila V, et al. SARS-CoV2 vertical transmission with adverse effects on the newborn revealed through integrated immunohistochemical, electron microscopy and molecular analyses of Placenta. EBioMedicine. 2020;59:102951. Doi: 10.1016/j.ebiom.2020.102951

18 Ferraiolo A, Barra F, Kratochwila C, Paudice M, Vellone VG, Godano E, et al. Report of positive placental swabs for SARS-CoV-2 in an asymptomatic pregnant woman with COVID-19. Medicina (Kaunas). 2020;56(06):306. Doi: 10.3390/medicina56060306

19 Shanes ED, Mithal LB, Otero S, Azad HA, Miller ES, Goldstein JA. Placental Pathology in COVID-19. Am J Clin Pathol. 2020;154(01): 23-32. Doi: 10.1093/ajcp/aqaa089

20 Patanè L, Morotti D, Giunta MR, Sigismondi C, Piccoli MG, Frigerio L, et al. Vertical transmission of coronavirus disease 2019: severe acute respiratory syndrome coronavirus 2 RNA on the fetal side of the placenta in pregnancies with coronavirus disease 2019-positive mothers and neonates at birth. Am J Obstet Gynecol MFM. 2020;2(03):100145. Doi: 10.1016/j.ajogmf.2020.100145

21 Chen S, Huang B, Luo DJ, Li X, Yang F, Zhao Y, Nie X, et al. [Pregnancy with new coronavirus infection: clinical characteristics and placental pathological analysis of three cases]. Zhonghua Bing Li Xue Za Zhi. 2020;49(05):418-423. Doi: 10.3760/cma.j. cn112151-20200225-00138Chinese.

22 Taglauer E, Benarroch Y, Rop K, Barnett E, Sabharwal V, Yarrington C, Wachman EM. Consistent localization of SARS-CoV-2 spike glycoprotein and ACE2 over TMPRSS2 predominance in placental villi of 15 COVID-19 positive maternal-fetal dyads. Placenta. 2020;100:69-74. Doi: 10.1016/j.placenta.2020.08.015

23 Jaiman S, Romero R, Pacora P, Jung E, Bhatti G, Yeo L, et al. Disorders of placental villous maturation in fetal death. J Perinat Med. 2020;•••:/j/jpme.ahead-of-print/jpm-2020-0030/jpm2020-0030.xml. Doi: 10.1515/jpm-2020-0030 [ahead of print]

24 Derricott $\mathrm{H}$, Jones RL, Heazell AE. Investigating the association of villitis of unknown etiology with stillbirth and fetal growth restriction - a systematic review. Placenta. 2013;34(10): 856-862. Doi: 10.1016/j.placenta.2013.07.003

25 Redline RW. The clinical implications of placental diagnoses. Semin Perinatol. 2015;39(01):2-8. Doi: 10.1053/j.semperi.2014.10.002

26 Khong TY, Mooney EE, Ariel I, Balmus NCM, Boyd TK, Brundler MA, et al. Sampling and Definitions of Placental Lesions: Amsterdam Placental Workshop Group Consensus Statement. Arch Pathol Lab Med. 2016;140(07):698-713. Doi: 10.5858/arpa.2015-0225-CC

27 Kim CJ, Romero R, Chaemsaithong P, Kim JS. Chronic inflammation of the placenta: definition, classification, pathogenesis, and clinical significance. Am J Obstet Gynecol. 2015;213(4, Suppl): S53-S69. Doi: 10.1016/j.ajog.2015.08.041

28 Katzman PJ. Chronic inflammatory lesions of the placenta and preterm birth. NeoReviews. 2016;17(02):e80-86. Doi: $10+1542$ / neo.17-2-e80

29 Mattuizzi A, Sauvestre F, André G, Poingt M, Camberlein C, Carles $D$, et al. Adverse perinatal outcomes of chronic intervillositis of unknown etiology: an observational retrospective study of 122 cases. Sci Rep. 2020;10(01):12611. Doi: 10.1038/s41598-02069191-9

30 Chen A, Roberts DJ. Placental pathologic lesions with a significant recurrence risk - what not to miss!. APMIS. 2018;126(07): 589-601. Doi: 10.1111/apm.12796

31 Ng WF, Wong SF, Lam A, Mak YF, Yao H, Lee KC, et al. The placentas of patients with severe acute respiratory syndrome: a pathophysiological evaluation. Pathology. 2006;38(03):210-218. Doi: 10.1080/00313020600696280

32 Jeong SY, Sung SI, Sung JH, Ahn YS, Kang ES, Chang YS, et al. MERS$\mathrm{CoV}$ infection in a pregnant woman in Korea. J Korean Med Sci. 2017;32(10):1717-1720. Doi: 10.3346/jkms.2017.32.10.1717 
33 Yang Z, Liu Y. Vertical transmission of severe acute respiratory syndrome coronavirus 2: a systematic review. Am J Perinatol. 2020;37(10):1055-1060. Doi: 10.1055/s-0040-1712161

34 Hoffmann M, Kleine-Weber H, Schroeder S, Krüger N, Herrler $\mathrm{T}$, Erichsen S, et al. SARS-CoV-2 cell entry depends on ACE2 and TMPRSS2 and is blocked by a clinically proven protease inhibitor. Cell. 2020;181(02):271-280.e8. Doi: 10.1016/j. cell.2020.02.052

35 Gheblawi M, Wang K, Viveiros A, Nguyen Q, Zhong JC, Turner AJ, et al. Angiotensin-converting enzyme 2: SARS-CoV-2 receptor and regulator of the renin-angiotensin system: celebrating the 20th anniversary of the discovery of ACE2. Circ Res. 2020;126(10): 1456-1474. Doi: 10.1161/CIRCRESAHA.120.317015
36 Jia HP, Look DC, Shi L, Hickey M, Pewe L, Netland J, et al. ACE2 receptor expression and severe acute respiratory syndrome coronavirus infection depend on differentiation of human airway epithelia. J Virol. 2005;79(23):14614-14621. Doi: 10.1128/ JVI.79.23.14614-14621.2005

37 Pique-Regi R, Romero R, Tarca AL, Luca F, Xu Y, Alazizi A, Leng Y, et al. Does the human placenta express the canonical cell entry mediators for SARS-CoV-2? eLife. 2020;9:e58716. Doi: 10.7554/ eLife.58716

38 Valdés G, Neves LA, Anton L, Corthorn J, Chacón C, Germain AM, et al. Distribution of angiotensin-(1-7) and ACE2 in human placentas of normal and pathological pregnancies. Placenta. 2006;27(2-3):200-207. Doi: 10.1016/j.placenta.2005.02.015 